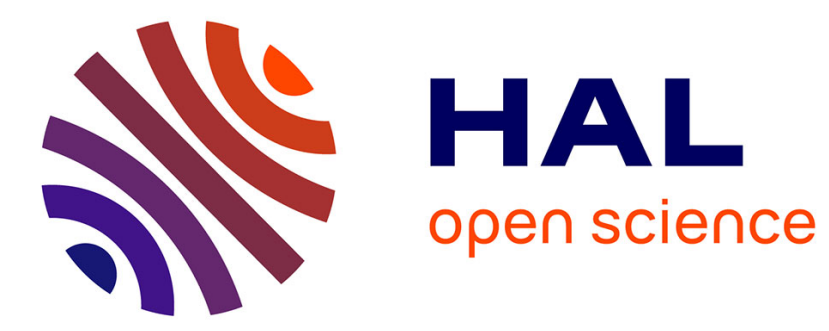

\title{
Mechanisms of endocrine disruption through nuclear receptors and related pathways
}

\author{
Patrick Balaguer, Vanessa Delfosse, William Bourguet
}

\section{To cite this version:}

Patrick Balaguer, Vanessa Delfosse, William Bourguet. Mechanisms of endocrine disruption through nuclear receptors and related pathways. Current Opinion in Endocrine and Metabolic Research, 2019, 7, pp.1-8. 10.1016/j.coemr.2019.04.008 . hal-02359583

\section{HAL Id: hal-02359583 https://hal.science/hal-02359583}

Submitted on 22 Nov 2019

HAL is a multi-disciplinary open access archive for the deposit and dissemination of scientific research documents, whether they are published or not. The documents may come from teaching and research institutions in France or abroad, or from public or private research centers.
L'archive ouverte pluridisciplinaire HAL, est destinée au dépôt et à la diffusion de documents scientifiques de niveau recherche, publiés ou non, émanant des établissements d'enseignement et de recherche français ou étrangers, des laboratoires publics ou privés. 


\section{Manuscript Details}

\section{Manuscript number}

Title

Short title

Article type
COEMR_2018_45

Mechanisms of endocrine disruption through nuclear receptors and related pathways

endocrine disruptors mechanisms of action

Review Article

\section{Abstract}

Endocrine-disrupting chemicals (EDCs) are a broad class of molecules present in our environment that are suspected to cause adverse effects in the endocrine system by interfering with the synthesis, transport, degradation or action of endogenous hormones. Humans are generally exposed to low doses of pollutants, and current researches aim at deciphering the mechanisms accounting for the health impact of EDCs at environmental concentrations. Here, we review different mechanisms through which EDCs might alter hormonal functions by interfering with the nuclear receptors and related pathways, including extranuclear signalling by membrane-bound receptors mediating rapid nongenomic responses, and the aryl hydrocarbon receptor (AhR).

\section{Keywords}

Manuscript region of origin

Corresponding Author

Corresponding Author's Institution

Order of Authors

Suggested reviewers nuclear receptors; dioxin receptor; endocrine-disrupting chemicals.

Europe

Patrick Balaguer

INSERM

Patrick Balaguer, Vanessa Delfosse, William Bourguet

Angel Nadal, Juliette Legler, Vincent Laudet

\section{Submission Files Included in this PDF}

\section{File Name [File Type]}

balaguer_main_text.docx [Manuscript File]

figure_1.tif [Figure]

figure_2.tif [Figure]

figure_3.tif [Figure]

To view all the submission files, including those not included in the PDF, click on the manuscript title on your EVISE Homepage, then click 'Download zip file'. 


\title{
Mechanisms of endocrine disruption through nuclear receptors and related pathways
}

Patrick Balaguer ${ }^{1}$, Vanessa Delfosse ${ }^{2}$ and William Bourguet ${ }^{2}$

${ }^{1}$ Institut de Recherche en Cancérologie de Montpellier (IRCM), Inserm, Univ Montpellier, ICM, Montpellier, France ; ${ }^{2}$ Centre de Biochimie Structurale (CBS), INSERM, CNRS, Univ Montpellier, France

\author{
Address correspondence to: \\ Patrick Balaguer. Telephone: +(33) 467612409. Fax: +(33) 467612337. E-mail: \\ patrick.balaguer@icm.unicancer.fr \\ William Bourguet Telephone: +(33) 467417702. Fax: +(33) 467417913. E-mail: \\ william.bourguet@cbs.cnrs.fr
}

\begin{abstract}
Endocrine-disrupting chemicals (EDCs) are a broad class of molecules present in our environment that are suspected to cause adverse effects in the endocrine system by interfering with the synthesis, transport, degradation or action of endogenous hormones. Humans are generally exposed to low doses of pollutants, and current researches aim at deciphering the mechanisms accounting for the health impact of EDCs at environmental concentrations. Here, we review different mechanisms through which EDCs might alter hormonal functions by interfering with the nuclear receptors and related pathways, including extranuclear signalling by membrane-bound receptors mediating rapid non-genomic responses, and the aryl hydrocarbon receptor (AhR).
\end{abstract}

Keywords: nuclear receptors; dioxin receptor; endocrine-disrupting chemicals. 


\section{Introduction}

Endocrine-disrupting chemicals (EDCs) are exogenous substances that interfere with the function of hormonal systems and produce a range of developmental, reproductive, neurological, immune or metabolic diseases in humans and wildlife [1-3]. Many EDCs are man-made chemicals produced by industry and released into the environment, but some naturally occurring EDCs can also be found in plants or fungi. The group of molecules acting as EDCs is highly heterogeneous and comprises compounds that are often distantly related to endogenous ligands in terms of size or chemical structure. This group contains substances as chemically different as bisphenols, phthalates, parabens, dioxins, alkylphenols, organotins, polychlorinated biphenyls, perfluoroalkyls, or benzophenones, as well as natural compounds such as the phytoestrogens genistein, daidzein or the mycoestrogen zearalenone. Since humans and wildlife are simultaneously and chronically exposed to low doses of multiple contaminants, understanding the molecular mechanisms underlying the physiological consequences of exposure to environmentally relevant concentrations of EDCs is a major challenge [4]. EDCs can affect the endocrine systems of an organism in a wide variety of ways. These include mimicking natural hormones, antagonizing their action or modifying their synthesis, metabolism and transport. As of today, most of the reported harmful effects of EDCs are attributed to their interaction with nuclear or extranuclear receptors that respectively function as transcriptional regulators in the nucleus such as the members of the nuclear receptors (NRs) superfamily [5,6] and the aryl hydrocarbon receptor (AhR) [7], or mediate rapid non-genomic responses, for instance, the membrane-associated nuclear receptors (mbNRs) [8] and the G protein-coupled receptor (GPCR) GPR30/GPER [9]. Herein, we review the main structural and molecular mechanisms used by EDCs to alter these signaling pathways and contribute to the etiology of several diseases. 


\section{Nuclear receptors are primary targets of EDCs}

The 48 human NRs control a plethora of biological processes such as development, organ homeostasis, metabolism, immune function, or reproduction [10,11]. As a consequence, inappropriate exposure to EDCs, can cause proliferative reproductive and metabolic disorders, including hormonal cancers, infertility and obesity. Most of the studies on EDCs have originally focused on NRs involved in reproductive processes, in particular the estrogen (ER $\alpha$ and $\mathrm{ER} \beta$ ) and the androgen (AR) receptors. However, mounting data reveal that most NRs are potential targets of EDCs. Among NRs, endogenous ligands have been identified for 24 family members. These receptors are ligand-dependent transcription factors that respond directly to a large variety of hormonal and metabolic substances that are hydrophobic, lipid soluble, and of small size (e.g. retinoic acid or estradiol). The other class of NRs is the group of so-called orphan receptors, for which regulatory ligands are still unknown or may not exist. The transcriptional activity of orphan receptors is thus regulated by post-translational modifications or cell-specific expression of coregulatory proteins, and eventually by pharmacological or environmental chemicals, as for instance the estrogen related receptor $\gamma$ $(\mathrm{ERR} \gamma)$ which has no endogenous ligand but is one of the main targets of bisphenol-A (BPA) [12]. All NR proteins exhibit a characteristic modular structure that consists of five domains (Fig. 1) [13]. The DNA-binding domain (DBD) is the most highly conserved domain and encodes two zinc finger modules. The ligand binding domain (LBD) is less conserved and mediates ligand binding, dimerization, and hosts a ligand-dependent transactivation function, termed AF-2 which corresponds to transcriptional coregulator interaction surfaces that are modulated by ligands. The remaining domains are the $\mathrm{N}$-terminal region containing a celland promoter specific transactivation function termed AF-1, the central hinge region linking 
the DBD and LBD, and the C-terminal region that is not present in all receptors and whose function is poorly understood.

\subsection{Genomic actions of nuclear receptors}

NRs may act either as repressors or activators of gene transcription depending on their ligandbinding status that in turn determines the ability of DNA-bound receptors to recruit coregulators to target gene promoters (Fig. 2). Coactivators and corepressors are large groups of proteins with a varied range of activities and enzymatic functions that contribute to transcription regulation by NRs and many other transcription factors, including AhR. Coactivators contribute to the enhancement of transcription by acetylating histones, a process that plays an important role in the opening of chromatin during transcription activation, whereas corepressors display the opposite activity by recruiting histone deacetylases (HDACs). Coactivator recruitment is usually ligand-dependent, whereas corepressors interact in most cases with unliganded receptors. In the absence of the cognate ligand, some NRs are located in the nucleus, bind to the DNA response elements of their target genes, and recruit corepressors, while others are located in the cytoplasm in an inactive complex with chaperones (Fig. 2). Ligand binding induces major structural alterations of the receptor LBDs leading to (i) destabilization of corepressor or chaperone interfaces, (ii) exposure of nuclear localization signals to allow nuclear translocation and DNA binding of cytoplasmic receptors, and (iii) recruitment of coactivators triggering gene transcription through chromatin remodelling and activation of the general transcription machinery.

\subsection{A structural view of the interaction between nuclear receptors and EDCs}

The LBD of NRs is composed of a conserved core of $12 \alpha$-helices (H1 to H12) and a short two-stranded antiparallel $\beta$-sheet (s1 and s2), arranged into a three-layered sandwich fold (Fig. 3A). This arrangement generates a mostly hydrophobic cavity, referred to as the ligandbinding pocket (LBP), which can accommodate the cognate ligand. In hormone-bound LBD 
structures, the LBP is sealed by helix H12, thus generating a hydrophobic binding groove for short LxxLL helical motifs ( $\mathrm{L}$ stands for leucine and $\mathrm{x}$ for any amino acid) found within coactivators. Biochemical and cell-based assays have revealed that EDCs bind to NRs with affinities ranging from sub-nanomolar to high micromolar values and structural analyses have revealed some mechanisms by which compounds structurally and chemically unrelated to physiological ligands can bind to NRs at environmentally relevant concentrations [14-16]. Representative examples are the binding of $\alpha$-zearalanol $(\alpha-\mathrm{ZA})$ to ER $\alpha$, the covalent interaction of various chemicals with the retinoid $\mathrm{X}$ receptor (RXR), the peroxisome proliferator-activated receptor $\gamma(\mathrm{PPAR} \gamma)$ and the xenobiotic receptor PXR, or the cooperative binding of two chemicals to PXR and PPAR $\gamma$. Even though the mycoestrogen $\alpha$-ZA (Fig. 1) is not a steroidal compound, it recapitulates the key interaction networks observed between the residues of the ER $\alpha$ LBP and the endogenous hormone $17 \beta$-estradiol $E_{2}$ (Fig. 3B). As such, $\alpha-Z A$ appears as an $E_{2}$ mimic that binds to its target receptor at sub-nanomolar concentrations [17]. In contrast, compounds of the organotin family such as the tributyltin (TBT, Fig. 1) bind with much avidity to many NRs through a mechanism that is totally different from those used by the natural or pharmacological ligands of these receptors. Indeed, the nanomolar affinity of organotins for NRs arises from the formation of a strong covalent bond formed between the tin atom of the chemical and the sulfur atom of a cysteine residue contained in the LBP of the receptors [14] (Fig. 3C). Beside tin compounds, many bioactive chemicals such as pesticides or drugs contain chemical groups that are prone to forming such covalent links with reactive cysteine residues, thereby insuring high affinity binding of the compounds. Structural studies have revealed that the insecticide fipronil and the herbicide pretilachlor bind to and activate PXR via this mechanism (our unpublished data). It is thus very likely that part of the low dose effects of a number of environmental compounds can be explained by their covalent interaction with the dozen NRs containing a cysteine residue in their LBP. Compared to 
binding sites located at the surface of proteins, the buried and mostly hydrophobic cavity provided by NRs probably offers an environment allowing a residence time long-enough to let the chemical reaction to occur. Finally, recent studies have shown that NR LBPs are more conformable than previously thought and can eventually accommodate several compounds simultaneously [18-22]. In some instances it has been shown that the compounds not only bind concomitantly to the receptor, but they do so cooperatively, i.e. the binding of one molecule promotes high affinity binding of the second, with synergistic effects on receptor function. Notably, the contraceptive 17a-ethinylestradiol (EE2, Fig. 1) and the persistent organochlorine pesticide trans-nonachlor (TNC, Fig. 1), both exhibiting low affinity and efficacy when studied separately, where shown to bind and activate the receptor PXR at much lower concentration when used in combination [20] (Fig. 3D).

\subsection{Non-genomic actions of nuclear receptors}

Beside their interference with the genomic pathways of NRs, EDCs have also been shown to interact with the membrane-associated fraction of these receptors (Fig. 2). Indeed, it is now well accepted that a small amount of NRs (a few percent) are positioned at the membrane (mbNRs) as previously shown for $\mathrm{ER} \alpha$ and $\beta$, and for many other NRs such as the progesterone, the androgen, the thyroid hormone or the vitamin D receptors [23-26]. As for $\mathrm{ER} \alpha$, the receptor is directed to the plasma membrane/caveloae via palmytoylation of an internal cysteine residue (C447) that is located in the LBD. Once localized in caveolae rafts, ligand-bound mbER $\alpha$ is depalmytoylated and interacts with and activates various Go and $\mathrm{G} \beta / \gamma$ proteins within seconds, thereby triggering a cascade of signal transduction including cAMP production, calcium mobilization, ion channel activation, endothelial nitric oxide synthase and multiple kinases (ERK and PI3K) activation [27]. It is interesting to note that mice expressing ER $\alpha$ mutated in this cysteine 447 (cysteine 451 in mice) are sterile (both males and females) and present differences in $E_{2}$ vascular actions, such as abrogation of 
endothelial repair and eNOS phosphorylation. In contrast, other responses like endometrial proliferation are similar to will-type mice [28]. These membrane-localized ERs are thought to mediate the rapid non genomic effects of natural $\left(\mathrm{E}_{2}\right)$ or environmental estrogens (BPA or alkylphenols) outside the nucleus $[28,29]$. Because the membrane-associated receptors are often the same proteins as their nuclear counterparts, one can make the assumption that compounds bind to the two receptor forms with the same mechanisms and thus similar binding affinities. However, it is not excluded that the membrane environment modifies the thermodynamics of the interactions with an impact on the ligand-binding properties of the receptor. Furthermore, it has been postulated that, in contrast to the nuclear pathway requiring ER-ligand complexes of sufficient lifetime to induce a long series of molecular events including dissociation from heat shock proteins, translocation, dimerization and DNA binding, recruitment of coregulators, alteration of chromatin architecture and finally transcription initiation, the extranuclear signalling pathway involving the rapid triggering of kinase cascades could be activated by ER-ligand complexes with shorter half-life [30]. In this context, one can note that the low binding affinity constant $(\mathrm{Kd})$ of compounds such as bisphenols and alkylphenols generally results from a high dissociation rate constant (Koff) so that their complexes with ER feature short lifetimes [31]. Although this hypothesis needs further investigations, it could explain that EDCs with about 10,000-fold less affinity than $\mathrm{E}_{2}$ for ERs can activate the extranuclear-initiated signaling pathway preferentially over the nuclear pathway.

\section{The aryl hydrocarbon receptor}

\subsection{AhR structure and function}

The Aryl hydrocarbon Receptor (AhR), also known as the dioxin receptor, is a liganddependent transcription factor belonging to the basic helix-loop-helix (bHLH) PER-ARNTSIM (PAS) protein family that binds to DNA following formation of a heterodimer with the 
AhR-nuclear translocator protein (ARNT) [32,7]. Although not members of the NR family, AhR and ARNT display structural and functional similarities with NRs such as a molecular organisation in four major domains including a DBD and LBD, or a transcriptional activity that is regulated by the presence of ligands and coregulators (Fig. 1). The N-terminal bHLH domain is involved in DNA recognition. The PAS domain exists as a tandem of two domains, PAS-A and PAS-B, respectively, each encompassing around 50 amino acids. The bHLH and PAS-A domains of both AhR and ARNT dimerize to form a stable DNA-bound heterodimer. In AhR, the PAS-B domain is responsible for ligand binding. The C-terminal part of the protein also includes a transcriptional activation domain (TAD). Several multi-domain crystal structures of AhR-ARNT heterodimers have been recently reported providing insights onto the modes of DNA binding and dimerization of the complex $[33,34]$. These structures are characterized by sophisticated domain interplay and reveal a highly intertwined architecture that bind to DNA via the positively charged residues of the bHLH domains. None of the structures reported yet contain the PAS-B region of AhR so that the detailed mechanisms of ligand-binding and protein activation remain largely elusive. However, together with the extended interdomain interfaces, the high structural dynamics of the AhR PAS-A domain suggest an allosteric communication route to mediate ligand-induced changes in the PAS-B domain to the DNA-binding bHLH domains, the C-terminal TAD or the nuclear localization sequence (NLS). AhR binds a selection of different endogenous ligands including tryptophanderived metabolites and several dietary indoles, and is involved in many cellular processes including cell proliferation and differentiation, immune response, inflammation and circadian rhythm regulation [7]. While AhR also functions as a sensor of exogenous chemicals and promotes metabolic clearance through the induction of metabolizing enzymes such as CYP1A1 and CYP1B1 upon activation by external compounds, it is known to mediate most of the toxic effects of a range of environmental contaminants such as polyaromatic 
hydrocarbons (PAHs) and dioxins. These toxic effects are numerous and include teratogenicity, immunosuppression, metabolic and endocrine disruption, skin toxicity and cancer. In the absence of ligand, AhR resides in the cytosolic compartment of the cell bound to a molecular chaperone complex containing Hsp90 and XAP2 (Fig. 2). Upon ligand binding AhR translocates from the cytosol to the cell nucleus where it forms a heterodimer with ARNT. The AhR-ARNT complex recognizes specific sequences of DNA called xenobiotic responsive element (XRE) in the promoter region of the target genes and activates transcription of these genes via the recruitment of transcriptional coactivators. The activity of the AhR-ARNT complex is negatively modulated by proteasomal degradation and the AhR repressor (AhRR) that interacts with ARNT and forms an AhRR-ARNT heterocomplex down regulating AhR signalling. In addition to its direct interaction with target gene promoters, AhR accomplishes some of its regulatory functions by modulating the activity of other transcriptions factors including ERs, AR, and many others [35]. The liganded AhR-ARNT heterodimer modulates estrogen and androgen signaling positively by physically associating with unliganded ERs and AR and bringing transcriptional coactivators to the promoters of these receptors [36]. In contrast, in presence of estrogens and androgens, the liganded AhRARNT represses estrogen and androgen mediated transcription by targeting ERs and AR to the Cul4B-based ubiquitin ligase complex for proteosomal degradation [37]. Thus it appears that $\mathrm{AhR}$ acts both as a transcription factor and as an ubiquitin ligase component to mediate different signaling pathways [35].

\subsection{AhR ligands and ligand binding}

Although AhR was originally discovered as a primary target of the toxic dioxin $(2,3,7,8$ tetrachloro-dibenzo-p-dioxin, TCDD, Fig. 1), it is now recognized that AhR is able to respond to hundreds of chemically diverse endogenous, dietary and environmental compounds, a number of these compounds interacting with the receptor at (sub)nanomolar concentrations 
[38]. AhR ligands include polychlorinated dibenzo-p-dioxins, dibenzofurans (Fig. 1), polychlorinated biphenyls (e.g. PCB126, Fig. 1), polycyclic aromatic hydrocarbons (PAHs) as benzo(a)pyrene $(\mathrm{BaP})$ and related PAHs compounds, including 3-methylcholanthrene (3MC) and $\beta$-naphtoflavone. Dietary compounds (3,3'diindoylmethane and indolo(3,2)carbazole) and endogenous metabolites, such as indirubin and 6-formyindolo(3,2)carbazole (FICZ, Fig. 1) are also known to act as AhR ligands. In addition to their high affinity, some AhR ligands such as dioxins are very resistant to metabolism, which appears to confer a greater toxicity when compared to that of compounds such as BAP or $3 \mathrm{MC}$ which are rapidly metabolized by CYP1A1 [38]. In contrast, the mechanism of carcinogenicity of some PAHs includes the production of highly reactive genotoxic metabolites. While no structure of the AhR LBD has been reported yet, molecular modelling using the structures of closely related PAS domains has suggested some molecular features accounting for its ligand-binding promiscuity and specificity [39]. In particular, mutational analysis, molecular modelling and molecular dynamics simulations have identified residues that control ligand preferences and the high dynamics of some structural elements rendering the AhR PAS-B domain malleable [40-44]. Interestingly, flexibility of some regions of the LBD is also a characteristic feature of the NR PXR which is another major chemical sensor known to induce the expression of detoxification proteins such as metabolizing enzymes and transporters upon activation by a broad range of chemicals [45]. PXR contains several loops clustering at the bottom of the LBD that confer a high plasticity allowing the ligand binding pocket of the receptor to adopt different shapes according to the bound ligands. Three of these flexible elements are found in a PXR-specific sequence of approximately 60 residues inserted between helices $\mathrm{H} 1$ and $\mathrm{H} 3$ that display high thermal $\mathrm{B}$ factors (indicating structural mobility) or are completely disordered as observed in the crystal structures. However, a striking difference between the two receptors is that AhR is recognized by a number of high affinity ligands like TCDD or 
FICZ (with nanomolar affinities), whereas PXR is essentially bound by compounds with affinities in the micromolar to sub-micromolar range [38]. One potential explanation for this difference may reside in the size of the binding cavity of the two receptors. Indeed, while PXR displays the largest binding pocket among all NRs with experimentally-determined volumes ranging from 1280 to $1600 \AA^{3}$ depending on the bound compound, homology modelling of the PAS-B domain of AhR suggests a volume of the binding pocket in the range $300-400 \AA^{3}$ [46]. As a consequence, ligands generally occupy only a small fraction of the PXR binding pocket so that compounds appear to interact loosely with the residues lining the cavity, whereas the smaller pocket size of AhR may result in tighter contacts and a more stable ligand-bound complex. Another difference between the two proteins is that AhR is more easily antagonized than PXR. Indeed, a number of potent AhR antagonists have been discovered a while ago [47-49], whereas the first PXR antagonist has been reported only very recently $[50,51]$. This observation is consistent with a smaller and more constrained binding pocket in AhR.

\section{4. $G$ protein-coupled receptor 30}

The G protein-coupled receptor 30 (GPR30) also referred to as G protein-coupled estrogen receptor (GPER) was also proposed to act as a non-classical estrogen receptor localized at the plasma membrane or the endoplasmic reticulum [52,53]. Originally, GPR30 was identified as an orphan receptor belonging to the family of 7-transmembrane-spanning GPCRs. Later on, several studies reported the activation of GPR30 by natural, environmental and pharmaceutical estrogens and antiestrogens (for a review see [54]), leading to its designation as GPER. However contradictory results concerning the ability of this receptor to bind estrogens have been reported. Binding of $E_{2}$ and several xenoestrogens to GPR30 was observed by some laboratories [53] whereas others failed to detect any interaction $[55,56]$. Finally, the transgenic KO for GPR30 do not display phenotypes that result from estrogen 
depletion suggesting that GPR30 is not a direct mediator of estrogen effects but could be rather a collaborator in non-nuclear functions of the nuclear ER [57,58]. Several selective GPR30 agonists and antagonists have been recently identified which will probably help characterizing the role GPR30 in these toxic effects in the future [9].

Acknowledgements: We would like to acknowledge the financial support from the Plan Cancer Inserm (projects SYNERPXR 2 and CONTERREC) and the ANSES, (projects EVALPE and XENOMIX).

Competing financial interests: The authors declare no competing financial interests. 


\section{Figure captions}

Fig. 1. Nuclear receptors, $A h R$ and GPR30 are the main known targets of endocrine disruptors. Structural organisation of proteins, and chemical structures of the associated EDCs mentioned in this review $(\mathrm{EE} 2=$ ethinylestradiol; $\mathrm{TNC}=$ trans-nonachlor; $\mathrm{TBT}=$ tributyltin; TCDD = 2,3,7,8-tetrachloro-dibenzo-p-dioxin; PCB-126 = polychlorinated biphenyl 126; $\mathrm{FICZ}=6$-formyindolo( 3,2$)$ carbazole) .

Fig. 2. EDCs targeted cellular pathways. 1 The genomic pathways of nuclear receptors (NRs) and AhR, 2 the extranuclear signalling pathway of membrane-bound NRs ( $\mathrm{mbNR}$ ), and $\mathbf{3}$ the G protein-coupled receptor 30 (GPER/GPR30) pathway.

Fig. 3. Different binding modes of EDCs observed with NRs. A. Conserved 3D-structure of the ligand binding domain of nuclear receptors (here, $\mathrm{ER} \alpha$ in complex with estradiol, $\mathrm{PDB}_{\mathrm{id}}=$ 3UUD). Close up view of the ligand binding pockets of $\mathbf{B}$. ER $\alpha$ in complex with $\alpha$-zearalanol $\left(\mathrm{PDB}_{\mathrm{id}}=4 \mathrm{MG} 8\right), \mathbf{C} . \mathrm{RXR}$ in complex with TBT $\left(\mathrm{PDB}_{\mathrm{id}}=3 \mathrm{E} 94\right)$, and D. PXR in complex with EE2 and TNC $\left(\mathrm{PDB}_{\mathrm{id}}=4 \mathrm{X} 1 \mathrm{G}\right)$. 


\section{References}

1. Zoeller RT, Bergman A, Becher G, Bjerregaard P, Bornman R, Brandt I, Iguchi T, Jobling S, Kidd KA, Kortenkamp A, Skakkebaek NE, Toppari J, Vandenberg LN (2014) A path forward in the debate over health impacts of endocrine disrupting chemicals. Environ Health 13:118

2. Gore AC, Chappell VA, Fenton SE, Flaws JA, Nadal A, Prins GS, Toppari J, Zoeller RT (2015) EDC-2: The Endocrine Society's Second Scientific Statement on EndocrineDisrupting Chemicals. Endocrine reviews 36 (6):E1-E150

3. Schug TT, Janesick A, Blumberg B, Heindel JJ (2011) Endocrine disrupting chemicals and disease susceptibility. The Journal of steroid biochemistry and molecular biology 127 (3-5):204-215

4. Kundakovic M, Gudsnuk K, Franks B, Madrid J, Miller RL, Perera FP, Champagne FA (2013) Sex-specific epigenetic disruption and behavioral changes following low-dose in utero bisphenol A exposure. Proceedings of the National Academy of Sciences of the United States of America 110 (24):9956-9961

5. Giulivo M, Lopez de Alda M, Capri E, Barcelo D (2016) Human exposure to endocrine disrupting compounds: Their role in reproductive systems, metabolic syndrome and breast cancer. A review. Environmental research 151:251-264

6. Delfosse V, Maire AL, Balaguer P, Bourguet W (2014) A structural perspective on nuclear receptors as targets of environmental compounds. Acta pharmacologica Sinica $36(1): 88-101$

7. Nebert DW (2017) Aryl hydrocarbon receptor (AHR): "pioneer member" of the basichelix/loop/helix per-Arnt-sim (bHLH/PAS) family of "sensors" of foreign and endogenous signals. Progress in lipid research 67:38-57 
8. Levin ER, Hammes SR (2016) Nuclear receptors outside the nucleus: extranuclear signalling by steroid receptors. Nature reviews 17 (12):783-797

9. Prossnitz ER, Arterburn JB (2015) International Union of Basic and Clinical Pharmacology. XCVII. G Protein-Coupled Estrogen Receptor and Its Pharmacologic Modulators. Pharmacological reviews 67 (3):505-540

10. Germain P, Staels B, Dacquet C, Spedding M, Laudet V (2006) Overview of nomenclature of nuclear receptors. Pharmacological reviews 58 (4):685-704

11. Lazar MA (2017) Maturing of the nuclear receptor family. The Journal of clinical investigation 127 (4):1123-1125

12. Tohme M, Prud'homme SM, Boulahtouf A, Samarut E, Brunet F, Bernard L, Bourguet W, Gibert Y, Balaguer P, Laudet V (2014) Estrogen-related receptor gamma is an in vivo receptor of bisphenol A. Faseb J 28 (7):3124-3133

13. Weikum ER, Liu X, Ortlund EA (2018) The nuclear receptor superfamily: A structural perspective. Protein Sci 27 (11):1876-1892

14. le Maire A, Grimaldi M, Roecklin D, Dagnino S, Vivat-Hannah V, Balaguer P, Bourguet W (2009) Activation of RXR-PPAR heterodimers by organotin environmental endocrine disruptors. EMBO Rep 10 (4):367-373

15. Delfosse V, Grimaldi M, Pons JL, Boulahtouf A, le Maire A, Cavailles V, Labesse G, Bourguet W, Balaguer P (2012) Structural and mechanistic insights into bisphenols action provide guidelines for risk assessment and discovery of bisphenol A substitutes. Proceedings of the National Academy of Sciences of the United States of America 109 (37):14930-14935

16. Riu A, Grimaldi M, le Maire A, Bey G, Phillips K, Boulahtouf A, Perdu E, Zalko D, Bourguet W, Balaguer P (2011) Peroxisome proliferator-activated receptor gamma is a 
target for halogenated analogs of bisphenol A. Environmental health perspectives 119 (9):1227-1232

17. Delfosse V, Grimaldi M, Cavailles V, Balaguer P, Bourguet W (2014) Structural and Functional Profiling of Environmental Ligands for Estrogen Receptors. Environmental health perspectives 122:1306-13

18. Waku T, Shiraki T, Oyama T, Maebara K, Nakamori R, Morikawa K (2010) The nuclear receptor PPARgamma individually responds to serotonin- and fatty acidmetabolites. Embo J 29 (19):3395-3407

19. Shang J, Brust R, Mosure SA, Bass J, Munoz-Tello P, Lin H, Hughes TS, Tang M, Ge Q, Kamenekca TM, Kojetin DJ (2018) Cooperative cobinding of synthetic and natural ligands to the nuclear receptor PPARgamma. eLife 7

* 20. Delfosse V, Dendele B, Huet T, Grimaldi M, Boulahtouf A, Gerbal-Chaloin S, Beucher B, Roecklin D, Muller C, Rahmani R, Cavailles V, Daujat-Chavanieu M, Vivat V, Pascussi JM, Balaguer P, Bourguet W (2015) Synergistic activation of human pregnane X receptor by binary cocktails of pharmaceutical and environmental compounds. Nature communications 6:8089

This article reports the first molecular description of a mechanism accounting for the cocktail effect of EDCs. The paper shows how two molecules of the environment can cooperate to increase their binding affinity for a nuclear receptor and stimulate its transcriptional activity at doses where the compounds alone are inactive.

21. Hughes TS, Giri PK, de Vera IM, Marciano DP, Kuruvilla DS, Shin Y, Blayo AL, Kamenecka TM, Burris TP, Griffin PR, Kojetin DJ (2014) An alternate binding site for PPARgamma ligands. Nature communications 5:3571

22. Hughes TS, Shang J, Brust R, de Vera IMS, Fuhrmann J, Ruiz C, Cameron MD, Kamenecka TM, Kojetin DJ (2016) Probing the Complex Binding Modes of the 
PPARgamma Partial Agonist 2-Chloro-N-(3-chloro-4-((5-chlorobenzo[d]thiazol-2yl)thio)phenyl)-4-(trifluorome thyl)benzenesulfonamide (T2384) to Orthosteric and Allosteric Sites with NMR Spectroscopy. Journal of medicinal chemistry 59 (22):1033510341

23. Anyetei-Anum CS, Roggero VR, Allison LA (2018) Thyroid hormone receptor localization in target tissues. The Journal of endocrinology 237 (1):R19-R34

24. Boonyaratanakornkit V, Hamilton N, Marquez-Garban DC, Pateetin P, McGowan EM, Pietras RJ (2018) Extranuclear signaling by sex steroid receptors and clinical implications in breast cancer. Molecular and cellular endocrinology 466:51-72

25. Trochoutsou AI, Kloukina V, Samitas K, Xanthou G (2015) Vitamin-D in the Immune System: Genomic and Non-Genomic Actions. Mini reviews in medicinal chemistry 15 (11):953-963

26. Rosenfeld CS, Cooke PS (2018) Endocrine disruption through membrane estrogen receptors and novel pathways leading to rapid toxicological and epigenetic effects. The Journal of steroid biochemistry and molecular biology 18:106-117

27. Levin ER (2015) Extranuclear steroid receptors are essential for steroid hormone actions. Annual review of medicine 66:271-280

* 28. Arnal JF, Lenfant F, Metivier R, Flouriot G, Henrion D, Adlanmerini M, Fontaine C, Gourdy P, Chambon P, Katzenellenbogen B, Katzenellenbogen J (2017) Membrane and Nuclear Estrogen Receptor Alpha Actions: From Tissue Specificity to Medical Implications. Physiological reviews 97 (3):1045-1087

This review is an excellent synthesis of current knowledge of the respective roles of nuclear and membrane forms of estrogen receptors. 
29. Villar-Pazos S, Martinez-Pinna J, Castellano-Munoz M, Alonso-Magdalena P, Marroqui L, Quesada I, Gustafsson JA, Nadal A (2017) Molecular mechanisms involved in the nonmonotonic effect of bisphenol-a on ca2+ entry in mouse pancreatic beta-cells. Scientific reports 7 (1):11770

* 30. Madak-Erdogan Z, Kim SH, Gong P, Zhao YC, Zhang H, Chambliss KL, Carlson KE, Mayne CG, Shaul PW, Korach KS, Katzenellenbogen JA, Katzenellenbogen BS (2016) Design of pathway preferential estrogens that provide beneficial metabolic and vascular effects without stimulating reproductive tissues. Science signaling 9 (429):ra53

This article described estrogens which preferentially activate membrane bound ER $\alpha$. Interestingly, some of these selective estrogens have a structure similar to that of bisphenol-A.

31. Rich RL, Hoth LR, Geoghegan KF, Brown TA, LeMotte PK, Simons SP, Hensley P, Myszka DG (2002) Kinetic analysis of estrogen receptor/ligand interactions. Proceedings of the National Academy of Sciences of the United States of America 99 (13):8562-8567

32. Guyot E, Chevallier A, Barouki R, Coumoul X (2013) The AhR twist: ligand-dependent AhR signaling and pharmaco-toxicological implications. Drug discovery today 18 (910):479-486

33. Seok SH, Lee W, Jiang L, Molugu K, Zheng A, Li Y, Park S, Bradfield CA, Xing Y (2017) Structural hierarchy controlling dimerization and target DNA recognition in the AHR transcriptional complex. Proceedings of the National Academy of Sciences of the United States of America 114 (21):5431-5436

34. Schulte KW, Green E, Wilz A, Platten M, Daumke O (2017) Structural Basis for Aryl Hydrocarbon Receptor-Mediated Gene Activation. Structure 25 (7):1025-1033 e1023 
35. Ohtake F, Fujii-Kuriyama Y, Kawajiri K, Kato S (2011) Cross-talk of dioxin and estrogen receptor signals through the ubiquitin system. The Journal of steroid biochemistry and molecular biology 127 (1-2):102-107

36. Ohtake F, Takeyama K, Matsumoto T, Kitagawa H, Yamamoto Y, Nohara K, Tohyama C, Krust A, Mimura J, Chambon P, Yanagisawa J, Fujii-Kuriyama Y, Kato S (2003) Modulation of oestrogen receptor signalling by association with the activated dioxin receptor. Nature 423 (6939):545-550

37. Ohtake F, Baba A, Takada I, Okada M, Iwasaki K, Miki H, Takahashi S, Kouzmenko A, Nohara K, Chiba T, Fujii-Kuriyama Y, Kato S (2007) Dioxin receptor is a liganddependent E3 ubiquitin ligase. Nature 446 (7135):562-566

38. Denison MS, Faber SC (2017) And Now for Something Completely Different: Diversity in Ligand-Dependent Activation of Ah Receptor Responses. Current opinion in toxicology 2:124-131

39. Bonati L, Corrada D, Tagliabue SG, Motta S (2017) Molecular modeling of the AhR structure and interactions can shed light on ligand-dependent activation and transformation mechanisms. Current opinion in toxicology 2:42-49

40. Pandini A, Soshilov AA, Song Y, Zhao J, Bonati L, Denison MS (2009) Detection of the TCDD binding-fingerprint within the Ah receptor ligand binding domain by structurally driven mutagenesis and functional analysis. Biochemistry 48 (25):5972-5983

41. Xing Y, Nukaya M, Satyshur KA, Jiang L, Stanevich V, Korkmaz EN, Burdette L, Kennedy GD, Cui Q, Bradfield CA (2012) Identification of the Ah-receptor structural determinants for ligand preferences. Toxicol Sci 129 (1):86-97

42. Nuti R, Gargaro M, Matino D, Dolciami D, Grohmann U, Puccetti P, Fallarino F, Macchiarulo A (2014) Ligand binding and functional selectivity of L-tryptophan 
metabolites at the mouse aryl hydrocarbon receptor (mAhR). Journal of chemical information and modeling 54 (12):3373-3383

43. Fraccalvieri D, Soshilov AA, Karchner SI, Franks DG, Pandini A, Bonati L, Hahn ME, Denison MS (2013) Comparative analysis of homology models of the AH receptor ligand binding domain: verification of structure-function predictions by site-directed mutagenesis of a nonfunctional receptor. Biochemistry 52 (4):714-725

44. Pandini A, Denison MS, Song Y, Soshilov AA, Bonati L (2007) Structural and functional characterization of the aryl hydrocarbon receptor ligand binding domain by homology modeling and mutational analysis. Biochemistry 46 (3):696-708

45. Mackowiak B, Wang H (2016) Mechanisms of xenobiotic receptor activation: Direct vs. indirect. Biochimica et biophysica acta 1859 (9):1130-1140

46. Perkins A, Phillips JL, Kerkvliet NI, Tanguay RL, Perdew GH, Kolluri SK, Bisson WH (2014) A Structural Switch between Agonist and Antagonist Bound Conformations for a Ligand-Optimized Model of the Human Aryl Hydrocarbon Receptor Ligand Binding Domain. Biology 3 (4):645-669

47. Kim SH, Henry EC, Kim DK, Kim YH, Shin KJ, Han MS, Lee TG, Kang JK, Gasiewicz TA, Ryu SH, Suh PG (2006) Novel compound 2-methyl-2H-pyrazole-3-carboxylic acid (2methyl-4-o-tolylazo-phenyl)-amide (CH-223191) prevents 2,3,7,8-TCDD-induced toxicity by antagonizing the aryl hydrocarbon receptor. Molecular pharmacology 69 (6):1871-1878

48. Smith KJ, Murray IA, Tanos R, Tellew J, Boitano AE, Bisson WH, Kolluri SK, Cooke MP, Perdew GH (2011) Identification of a high-affinity ligand that exhibits complete aryl hydrocarbon receptor antagonism. The Journal of pharmacology and experimental therapeutics 338 (1):318-327 
49. Parks AJ, Pollastri MP, Hahn ME, Stanford EA, Novikov O, Franks DG, Haigh SE, Narasimhan S, Ashton TD, Hopper TG, Kozakov D, Beglov D, Vajda S, Schlezinger JJ, Sherr DH (2014) In silico identification of an aryl hydrocarbon receptor antagonist with biological activity in vitro and in vivo. Molecular pharmacology 86 (5):593-608

** 50. Lin W, Wang YM, Chai SC, Lv L, Zheng J, Wu J, Zhang Q, Wang YD, Griffin PR, Chen T (2017) SPA70 is a potent antagonist of human pregnane $\mathrm{X}$ receptor. Nature communications $8(1): 741$

This article describes the first potent PXR antagonist which constitutes an invaluable tool to study the functions of this nuclear receptor which is a first-line target of EDCs.

51. Lin W, Chen T (2017) Using TR-FRET to Investigate Protein-Protein Interactions: A Case Study of PXR-Coregulator Interaction. Advances in protein chemistry and structural biology 110:31-63

52. Revankar CM, Cimino DF, Sklar LA, Arterburn JB, Prossnitz ER (2005) A transmembrane intracellular estrogen receptor mediates rapid cell signaling. Science (New York, NY 307 (5715):1625-1630

53. Thomas P, Pang Y, Filardo EJ, Dong J (2005) Identity of an estrogen membrane receptor coupled to a G protein in human breast cancer cells. Endocrinology 146 (2):624-632

54. Barton M, Filardo EJ, Lolait SJ, Thomas P, Maggiolini M, Prossnitz ER (2018) Twenty years of the G protein-coupled estrogen receptor GPER: Historical and personal perspectives. The Journal of steroid biochemistry and molecular biology 176:4-15

55. Pedram A, Razandi M, Levin ER (2006) Nature of functional estrogen receptors at the plasma membrane. Molecular endocrinology (Baltimore, Md 20 (9):1996-2009

56. Otto C, Rohde-Schulz B, Schwarz G, Fuchs I, Klewer M, Brittain D, Langer G, Bader B, Prelle K, Nubbemeyer R, Fritzemeier KH (2008) G protein-coupled receptor 30 localizes 
to the endoplasmic reticulum and is not activated by estradiol. Endocrinology 149 (10):4846-4856

57. Levin ER (2009) Plasma membrane estrogen receptors. Trends in endocrinology and metabolism: TEM 20 (10):477-482

58. Romano SN, Gorelick DA (2018) Crosstalk between nuclear and G protein-coupled estrogen receptors. General and comparative endocrinology 261:190-197 


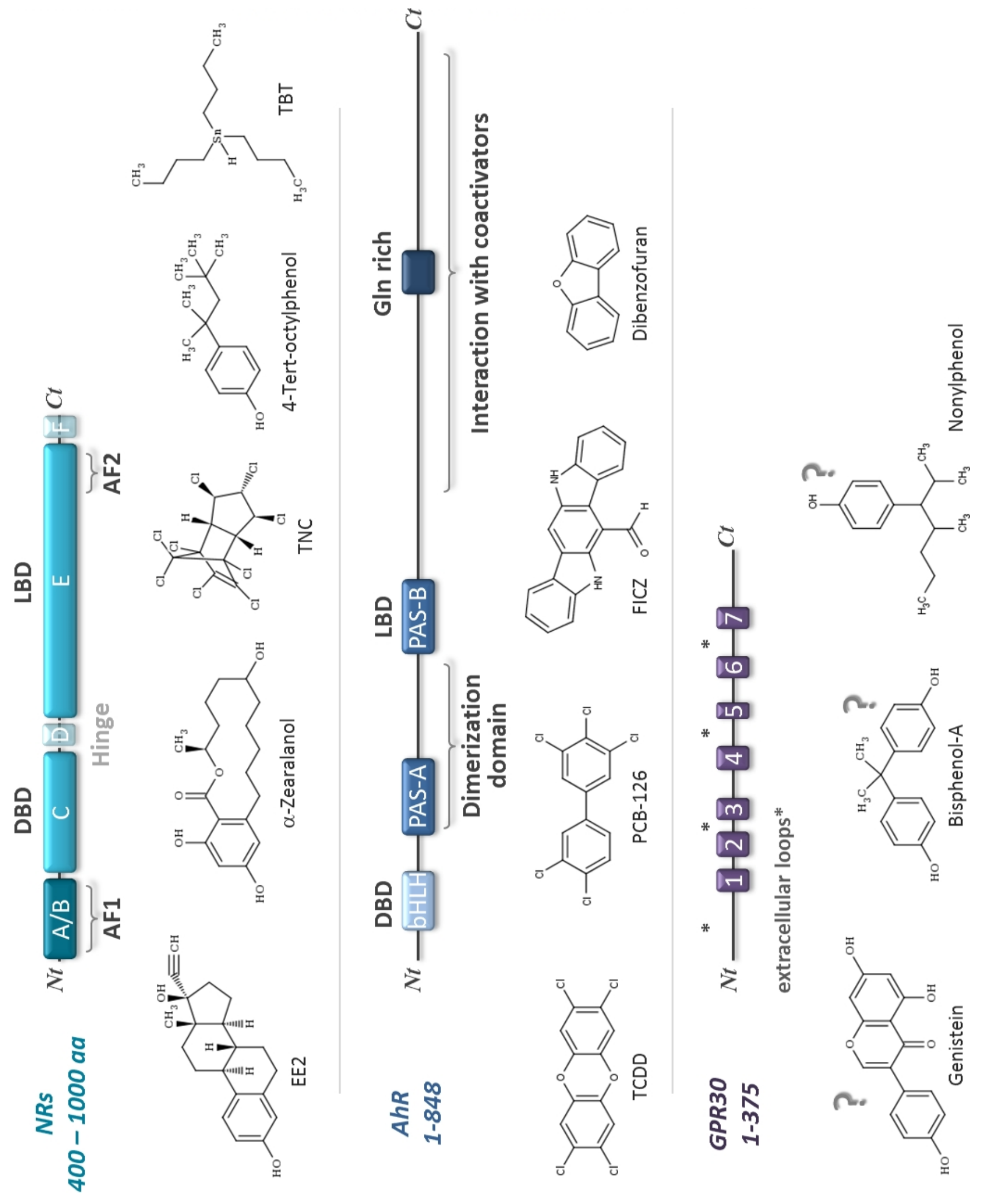




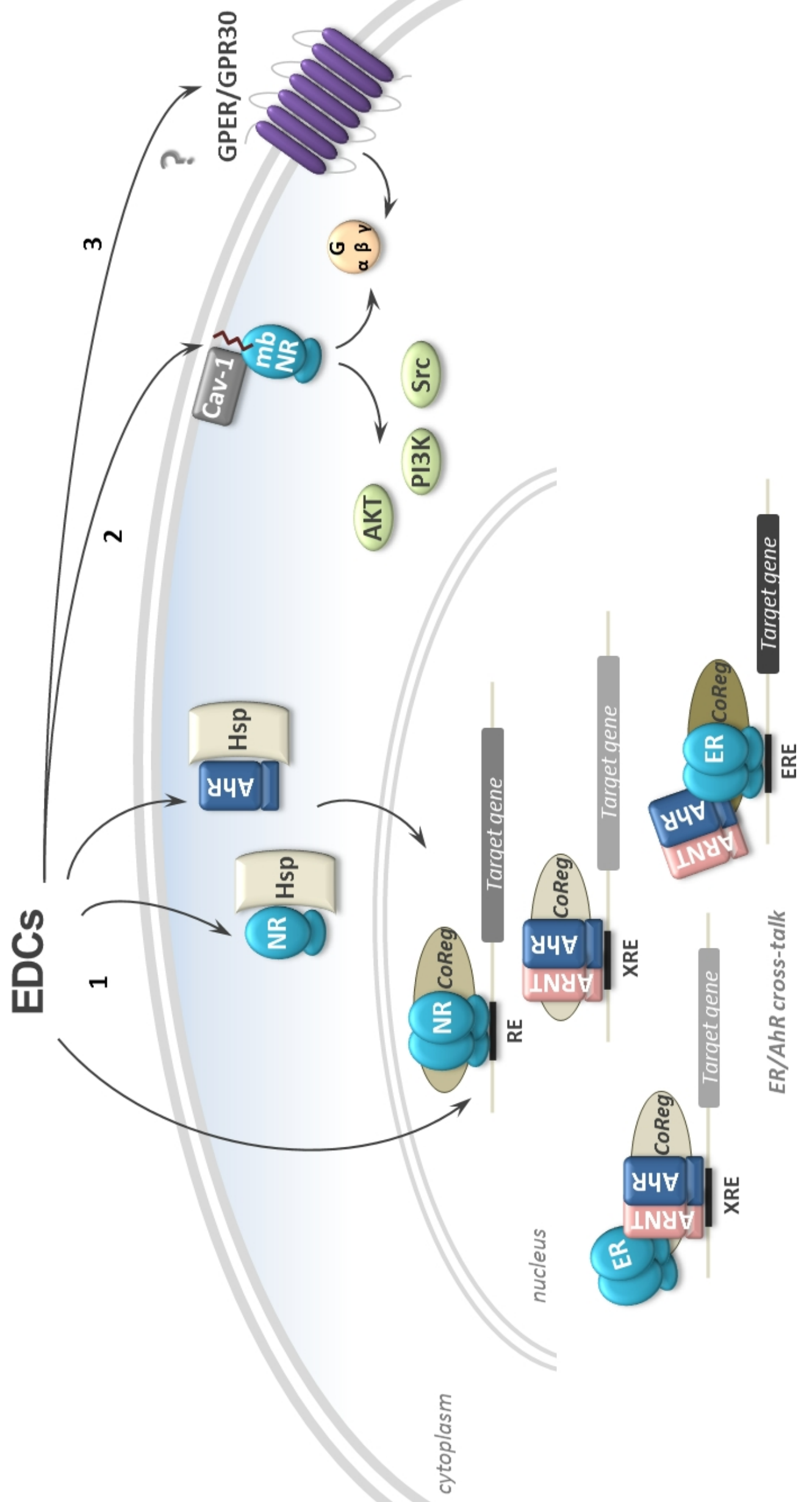




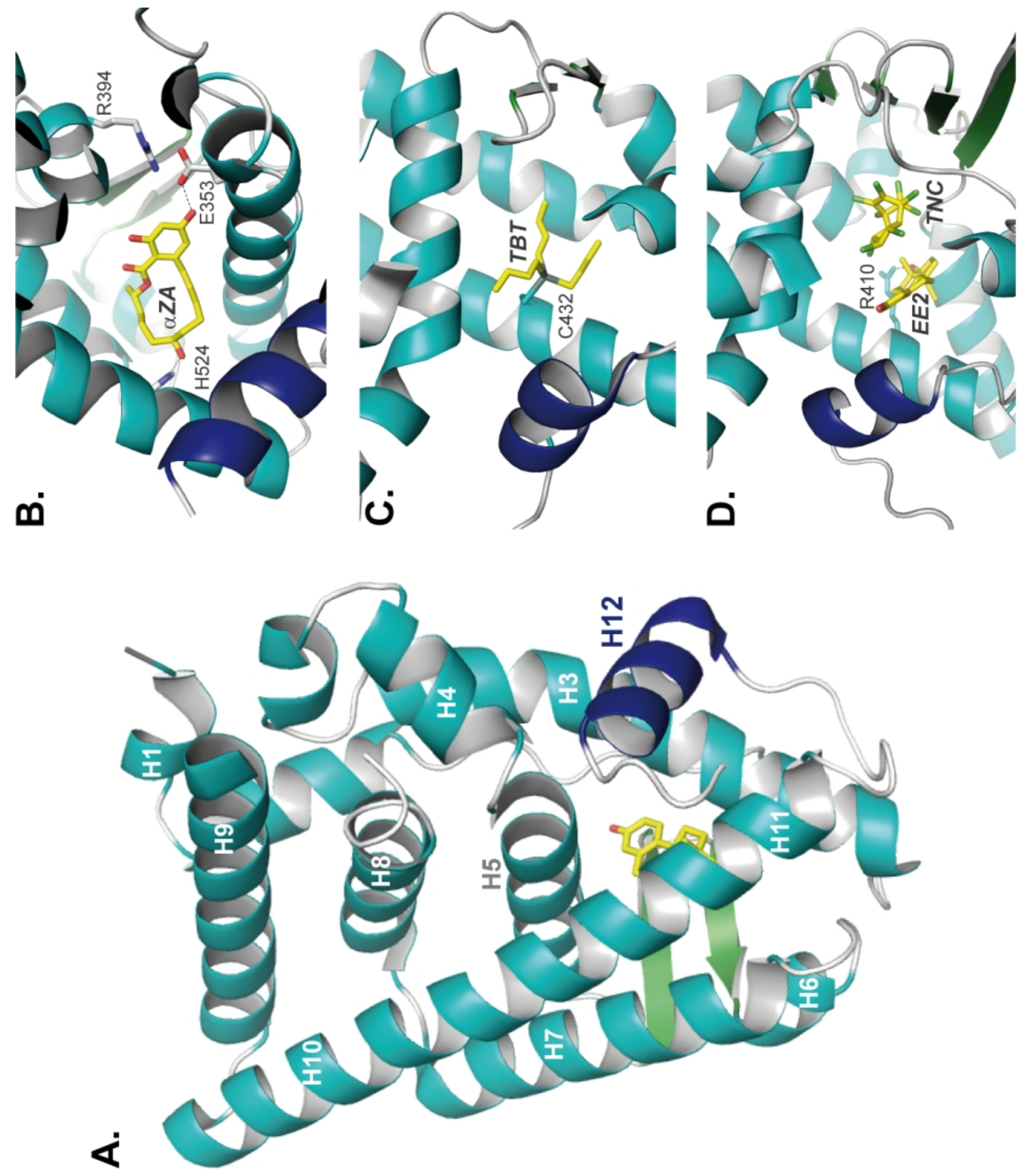

